\title{
Derivation and internal validation of the screening to enhance prehospital identification of sepsis (SEPSIS) score in adults on arrival at the emergency department
}

\author{
Michael A. Smyth ${ }^{1,2,3^{*}}$, Daniel Gallacher ${ }^{1}$, Peter K. Kimani ${ }^{1}$, Mark Ragoo ${ }^{4}$, Matthew Ward ${ }^{2}$ and Gavin D. Perkins ${ }^{1,5}$
}

\begin{abstract}
Background: Prehospital recognition of sepsis may inform case management by ambulance clinicians, as well as inform transport decisions. The objective of this study was to develop a prehospital sepsis screening tool for use by ambulance clinicians.

Methods: We derived and validated a sepsis screening tool, utilising univariable logistic regression models to identify predictors for inclusion, and multivariable logistic regression to generate the SEPSIS score. We utilised a retrospective cohort of adult patients transported by ambulance $(n=38483)$ to hospital between 01 July 2013 and 30 June 2014. Records were linked using LinkPlus ${ }^{\circledR}$ software. Successful linkage was achieved in 33289 cases (86\%). Eligible patients included adult, non-trauma, non-mental health, non-cardiac arrest cases. Of 33289 linked cases, 22945 cases were eligible. Eligible cases were divided into derivation $(n=16063,70 \%)$ and validation $(n=6882$, 30\%) cohorts. The primary outcome measure was high risk of severe illness or death from sepsis, as defined by the National Institute for Health and Care Excellence Sepsis guideline.

Results: 'High risk of severe illness or death from sepsis' was present in $3.7 \%$ of derivation $(n=593)$ and validation ( $n=254)$ cohorts. The SEPSIS score comprises the following variables: age, respiratory rate, peripheral oxygen saturations, heart rate, systolic blood pressure, temperature and level of consciousness ( $p<0.001$ for all variables). Area under the curve was $0.87(95 \% \mathrm{Cl} 0.85-0.88)$ for the derivation cohort, and $0.86(95 \% \mathrm{Cl} 0.84-0.88)$ for the validation cohort. In an undifferentiated adult medical population, for a SEPSIS score $\geq 5$, sensitivity was 0.37 (0.31$0.44)$, specificity was $0.96(0.96-0.97)$, positive predictive value was $0.27(0.23-0.32)$, negative predictive value was 0.97 (0.96-0.97), positive likelihood value was 13.5 (9.7-18.73) and the negative likelihood value was 0.83 (0.78-0.88).

Conclusion: This is the first screening tool developed to identify NICE high risk of severe illness or death from sepsis. The SEPSIS score is significantly associated with high risk of severe illness or death from sepsis on arrival at the Emergency Department. It may assist ambulance clinicians to identify those patients with sepsis in need of antibiotic therapy. However, it requires external validation, in clinical practice by ambulance clinicians, in an independent population.
\end{abstract}

Keywords: Sepsis, Prehospital, Ambulance, Screening tool, Prediction model

\footnotetext{
* Correspondence: m.a.smyth@warwick.ac.uk

${ }^{1}$ Clinical Trials Unit, University of Warwick, Coventry, UK

${ }^{2}$ West Midlands Ambulance Service NHS Foundation Trust, Dudley, UK

Full list of author information is available at the end of the article
}

(c) The Author(s). 2019 Open Access This article is distributed under the terms of the Creative Commons Attribution 4.0 International License (http://creativecommons.org/licenses/by/4.0/), which permits unrestricted use, distribution, and reproduction in any medium, provided you give appropriate credit to the original author(s) and the source, provide a link to the Creative Commons license, and indicate if changes were made. The Creative Commons Public Domain Dedication waiver (http://creativecommons.org/publicdomain/zero/1.0/) applies to the data made available in this article, unless otherwise stated. 


\section{Introduction}

Sepsis is a common and potentially life threatening response to an infection [1]. Worldwide there are an estimated 31.5 million cases of uncomplicated sepsis and 19.4 million cases of severe sepsis or septic shock resulting in 5.3 million deaths each year [2]. The majority of these cases originate in the community and will present to hospital via the Emergency Department (ED) [3, 4]. More than half of ED sepsis cases will arrive via Emergency Medical Services (EMS) [5-10]. These patients are likely to be sicker than those arriving by other means $[6,8-11]$.

International guidelines for sepsis advocate that treatment be initiated at the earliest possible opportunity [1, 12]. Recent data suggest each hour delay to antibiotic therapy results in an increase in mortality among patients with septic shock of $2.8 \%$ [13] whereas for each hour delay in delivering a $3 \mathrm{~h}$ resuscitation bundle (intravenous antibiotics, vascular therapy and obtaining blood cultures) sees a $4 \%$ increase in mortality [14]. Early EMS intervention has helped to improve outcomes for other time critical, life-threatening conditions such as acute myocardial infarction [15], stroke [16] and major trauma [17]. It remains to be seen if early EMS intervention in sepsis improves outcomes.

Small observational studies indicate prehospital care reduces time to antibiotics for patients with sepsis, without improving clinical outcomes $[5,18,19]$. Thus far, trials of prehospital antibiotics have failed to demonstrate improved clinical outcomes [20, 21]. One potential reason for this is inclusion of low acuity sepsis patients within prehospital studies [21].

Despite frequent exposure to patients with potentially life-threatening sepsis [22], prehospital recognition of sepsis is challenging [18, 23-27]. Indeed, a recent analysis of 240 patients transported by Ambulance Victoria, who were subsequently enrolled in the ARISE study, showed that despite the presence of demonstrable physiologic abnormalities, only 165 patients had documentation of infection in their prehospital record [28]. There are several reasons why this may be so, including, suboptimal teaching and understanding of the condition [6, 29-31], encountering sepsis cases earlier in the disease process when the clinical presentation is less obvious [32], lack of inhospital diagnostic capability [18] and dependence upon SIRS criteria to formulate a diagnosis [33, 34]. Reliance upon paramedic gestalt may therefore mean patients with significant pathology are not identified until after arrival at hospital. It has been argued that a prehospital sepsis screening tool to assist prehospital clinicians identify 'sick' sepsis patients would be helpful $[6,35]$.

The NICE guideline "Recognition and management of sepsis (NG51)", stratifies the risk of "severe illness or death from sepsis" (see Table 1) [12]. It recommends that patients categorised as "high risk of severe illness or death from sepsis" should receive antibiotics within $1 \mathrm{~h}$ [12]. The aim of this study was to develop a simple scoring system that would help identify those adult patients who might benefit most from early intervention. For brevity we refer to the NICE categorisation of "high risk of severe illness or death from sepsis" as 'high risk'.

\section{Methods}

\section{Study design and population}

This study was conducted and reported consistent with TRIPOD reporting guidelines [36]. We utilised a retrospective sample of consecutive adult patients (age $\geq 18$ years) transported by West Midlands Ambulance Service NHS Foundation Trust (WMAS) to Royal Stoke University Hospital NHS Trust (previously University Hospital North Staffordshire NHS Foundation Trust) between 01 July 2013 and 30 June 2014. Exclusion criteria were age under 18 years, cardiac arrest, trauma or mental health aetiology (determined from hospital discharge diagnosis). No interventions were undertaken as part of this study.

\section{Patient involvement}

A study committee was convened to oversee the Clinical Doctoral Research Fellowship awarded to MAS. This committee included a patient representative who contributed to the initial research plan, and commented on chapters of the doctoral thesis. The patient representative did not contribute to writing or reviewing this manuscript.

\section{Primary outcome measure}

The primary outcome measure was categorisation as 'high risk of severe illness or death from sepsis', as per the National Institute for Health and Care Excellence (NICE) Guideline "Recognition and management of sepsis (NG51)" [12], on arrival at the ED. For each included patient, category of 'risk of severe illness or death from sepsis' was assigned as 'no risk' i.e. no infection present, 'low risk', 'moderate risk' or 'high risk', dependent upon presence of infection and presenting vital signs. Presence of infection was determined using the ED discharge diagnosis. Classification of the risk of severe illness or death from sepsis was determined utilising clinical data recorded in the ED in accordance with Table 1.

\section{Record linkage}

LinkPlus $^{\oplus}$ software (version 3.0 beta, Centres for Disease Control and Prevention Cancer Division, Atlanta, Georgia), a probabilistic linkage program was used to link ambulance and ED records. First name, surname, gender, date of birth, home address post code and incident date were used to link records. All candidate record pairs were manually reviewed. Following linkage patient identifiable data were deleted. 
Table 1 NICE Risk of severe illness or death from sepsis

\begin{tabular}{|c|c|c|c|}
\hline Category & High risk criteria & Moderate to high risk criteria & Low risk criteria \\
\hline History & Objective evidence of new altered mental state & $\begin{array}{l}\text { History from patient, friend or relative of new } \\
\text { onset of altered behaviour or mental state } \\
\text { History of acute deterioration of functional ability } \\
\text { Impaired immune system (illness or drugs } \\
\text { including oral steroids) } \\
\text { Trauma, surgery or invasive procedures in the last } \\
6 \text { weeks }\end{array}$ & Normal behaviour \\
\hline Respiratory & $\begin{array}{l}\text { Raised respiratory rate: } 25 \text { breaths per minute or more } \\
\text { New need for oxygen (more than } 40 \% \mathrm{FiO} 2 \text { ) to maintain } \\
\text { saturation more than } 92 \% \text { (or more than } 88 \% \text { in known } \\
\text { chronic obstructive pulmonary disease) }\end{array}$ & Raised respiratory rate: $21-24$ breaths per minute & $\begin{array}{l}\text { No high risk or } \\
\text { moderate to high } \\
\text { risk criteria met }\end{array}$ \\
\hline $\begin{array}{l}\text { Blood } \\
\text { pressure }\end{array}$ & $\begin{array}{l}\text { Systolic blood pressure } 90 \mathrm{mmHg} \text { or less or systolic blood } \\
\text { pressure more than } 40 \mathrm{mmHg} \text { below normal }\end{array}$ & Systolic blood pressure $91-100 \mathrm{mmHg}$ & $\begin{array}{l}\text { No high risk or } \\
\text { moderate to high } \\
\text { risk criteria met }\end{array}$ \\
\hline $\begin{array}{l}\text { Circulation } \\
\text { and } \\
\text { hydration }\end{array}$ & $\begin{array}{l}\text { Raised heart rate: more than } 130 \text { beats per minute Not } \\
\text { passed urine in previous } 18 \mathrm{~h} \text {. } \\
\text { For catheterised patients, passed less than } 0.5 \mathrm{ml} / \mathrm{kg} \text { of urine } \\
\text { per hour }\end{array}$ & $\begin{array}{l}\text { Raised heart rate: } 91-130 \text { beats per minute (for } \\
\text { pregnant women } 100-130 \text { beats per minute) or } \\
\text { new onset arrhythmia } \\
\text { Not passed urine in the past } 12-18 \mathrm{~h} \\
\text { For catheterised patients, passed } 0.5-1 \mathrm{ml} / \mathrm{kg} \text { of } \\
\text { urine per hour }\end{array}$ & $\begin{array}{l}\text { No high risk or } \\
\text { moderate to high } \\
\text { risk criteria met }\end{array}$ \\
\hline Temperature & & Tympanic temperature less than $36^{\circ} \mathrm{C}$ & \\
\hline Skin & $\begin{array}{l}\text { Mottled or ashen appearance Cyanosis of skin, lips or } \\
\text { tongue Non-blanching rash of skin }\end{array}$ & $\begin{array}{l}\text { Signs of potential infection, including redness, } \\
\text { swelling or discharge at surgical site or } \\
\text { breakdown of wound }\end{array}$ & $\begin{array}{l}\text { No non-blanching } \\
\text { rash }\end{array}$ \\
\hline
\end{tabular}

\section{Missing data}

Statistical analyses were performed using $\mathrm{R}$ (version 3.3.1) in R Studio (version 0.99.903). Missing data were processed by multiple imputation using the $\mathrm{R}$ package Multiple Imputation by Chained Equations (MICE) (version 2.25) [37] with a Fully Conditional Specification. To ensure robust imputation of missing values, the number of imputed datasets required was slightly higher than the percentage of cases with incomplete data. For example if $18 \%$ of cases had incomplete data 20 imputations would be required. Variables that were functions of another variable were not imputed, rather their component variables were imputed and the function determined after imputation. For example, Glasgow Coma Score (GCS) sum is a function of three variables GCS eye, GCS verbal and GCS motor. GCS sum was not imputed, rather GCS eye, GCS verbal and GCS motor were imputed and GCS sum was calculated from the component values.

Satisfactory imputation of missing data was confirmed by inspection of both convergence plots and density plots of imputed values and observed data ( $R$ package MICE (version 2.25) [37] as well as calculation of R-hat convergence statistics using the $\mathrm{R}$ package MICEadds (version 1.9-0) [38].

\section{Model development}

Following the imputation of missing data we developed a multivariable logistic model for high risk of severe illness or death from sepsis ('high risk') on arrival at the
ED using several steps. First, the data were divided into derivation and validation cohorts using the $\mathrm{R}$ package Caret (version 6.0-71) [39]. The number of cases assigned to the derivation and validation cohorts were based upon recommendations by Harrell, Royston, Steyerberg and Vergouwe [40-47]. It has been argued that, when developing a predictive model, at least ten instances of the outcome of interest are required, per candidate predictor included in the model, to ensure statistically valid results [40-46]. Similarly, Vergouwe et al [47] argue that at least 100 events and 100 non-events are required to assess model performance in the validation dataset. However, Steyerberg [45] suggests that, to detect small differences in model performance, the validation dataset should contain at least 250 cases of the outcome of interest.

Derivation of the SEPSIS score was undertaken using the derivation dataset. We assessed the quality of candidate predictor variables using univariable logistic regression. Then, we constructed candidate parsimonious multivariable logistic models. Next, we assigned weighted point scores to included predictor variables. Thereafter we compared the performance of candidate models. Finally, we undertook internal validation of the SEPSIS score using the validation dataset.

Simple logistic regression was undertaken in an attempt to quantify the relationship between individual candidate predictor variables and the primary outcome measure ('high risk'). It is common at this stage to exclude variables that are not statistically associated with 
the outcome of interest however we did not, as to do so may exclude clinically important variables [45]. Candidate predictor variables were assessed for multicollinearity using the R package Caret (version 6.0-71) [39], any variables with a correlation coefficient above 0.9 (positive or negative) were considered to be highly collinear. Inclusion of multiple variables with high collinearity was avoided, either by exclusion of redundant variables, or by generation of parallel candidate models that did not contain multiple highly collinear variables.

Selection of independent predictor variables was informed by previously demonstrated clinical usefulness and by backward stepwise selection using the Akaike Information Criterion (AIC) and the Wald test $p$-value. Relative performance of candidate models was assessed by determining the AIC and Brier Score for each model.

Many paramedics will not have access to resources to calculate a complex model in clinical practice. Therefore, to simplify the models for use at the roadside, continuous variables were transformed into categorical variables by subdividing the variable range into intervals.

Variable intervals were determined by visual inspection of Loess curves and cut points were calculated using $\mathrm{R}$ the package OptimalCutPoints (version 1.1-3) [48]. We also considered normal physiologic ranges and intervals utilised in alternate sepsis screening tools. We recognise that conversion of continuous variables to categorical variables results in loss of precision. To guard against the loss of precision, continuous predictor variables were initially subdivided into multiple small intervals. Weighted scores were assigned to each interval by rounding the regression coefficient for each interval to the nearest integer. Intervals with equally weighted scores were subsequently merged to generate fewer, wider intervals, to simplify use by bed-side clinicians.

\section{Model performance}

Model performance was assessed using the validation dataset. Model calibration (goodness of fit) was assessed by calculation of the calibration slope ( $R$ package ResourceSelection (version 0.3-1)) [49]. The calibration slope is a graphical assessment of the relationship between predicted and observed outcomes [50], with predictions represented on the $\mathrm{x}$-axis, and outcomes represented on the $y$-axis. Perfect predictions fall on the $45^{\circ}$ line (calibration slope $=1$ ) [51]. The HosmerLemeshow goodness of fit test was not used to assess goodness of fit as a significant result, suggesting inadequate fit, is common when using large datasets [52]. Model discrimination was assessed by calculating the area under the receiver operating characteristic curve (AUROC) (R package ROCR (version 1.0-5) [53]. Model performance was assessed by calculating sensitivity, specificity, positive predictive value, negative predictive value, positive likelihood ratio and negative likelihood ratio ( $R$ package epiR (version 0.9-77) [54]).

\section{Ethical approval}

Permission to access patient identifiable data without consent was granted by the Health Research Authority (HRA) Confidentiality Advisory Committee (CAG) (CAG 4-03(PR2)2014). A favourable ethical opinion was obtained from the National Research Ethics Service (NRES) Committee South Central - Oxford C (14/SC/ 0163). Data storage and handling were conducted in accordance with WMAS standard operating procedures.

\section{Results}

From 38,483 unique ambulance records, LinkPlus ${ }^{\circ}$ generated 35,382 candidate record pairs. Manual review of all candidate pairs confirmed 33,289 (86.5\%) were correctly linked with their corresponding ED record. Following removal of excluded case aetiologies, 22,945 cases remained (see Fig. 1). Of the 5,194 (13.5\%) unlinked ambulance cases, a significant proportion were transported to hospital destinations other than the ED, for example the Medical Admission Unit (MAU). An initial review of 120 unlinked cases confirmed that 97 (80.8\%) were transported to hospital destinations other than the ED. A small proportion of unlinked cases result from an ambulance crew being unable to identify a patient in the early stages of their health care episode, for example when a patient is unconscious and their name cannot be determined. There were 58 instances $(1.1 \%$ of unlinked cases) where the name or surname fields of the ambulance record were "missing" or "unknown".

Of 54 potential variables, 30 were deemed inappropriate for inclusion in the model (Additional file 1: Table S1). Of 24 included variables, four (blood sugar, temperature, capillary bed refill time (CBRT) and skin) had greater than $10 \%$ missing values; and four (left pupil reaction, left pupil size, right pupil reaction and right pupil size) had between 5 and 10\% missing values. The remaining 16 variables had fewer than 2\% missing values. There were no cases where the ED discharge diagnosis field was empty.

Of the 22,945 included cases, only 12,517 (54.6\%) had complete data, all other cases had at least one missing data point. To ensure robust imputation 50 imputed datasets were generated. Convergence plots (Additional file 1: Figure S1), density plots (Additional file 1: Figure S2), Box and whisker plots (Additional file 1: Figure S3) and R-hat statistics (Additional file 1: Table S2) indicate that healthy convergence was achieved for all imputed variables except Left Pupil Size and Right Pupil size.

The dataset used comprised 24 variables, therefore to calculate reliable estimates, the derivation dataset must include at least 240 instances of 'high risk'. The imputed 


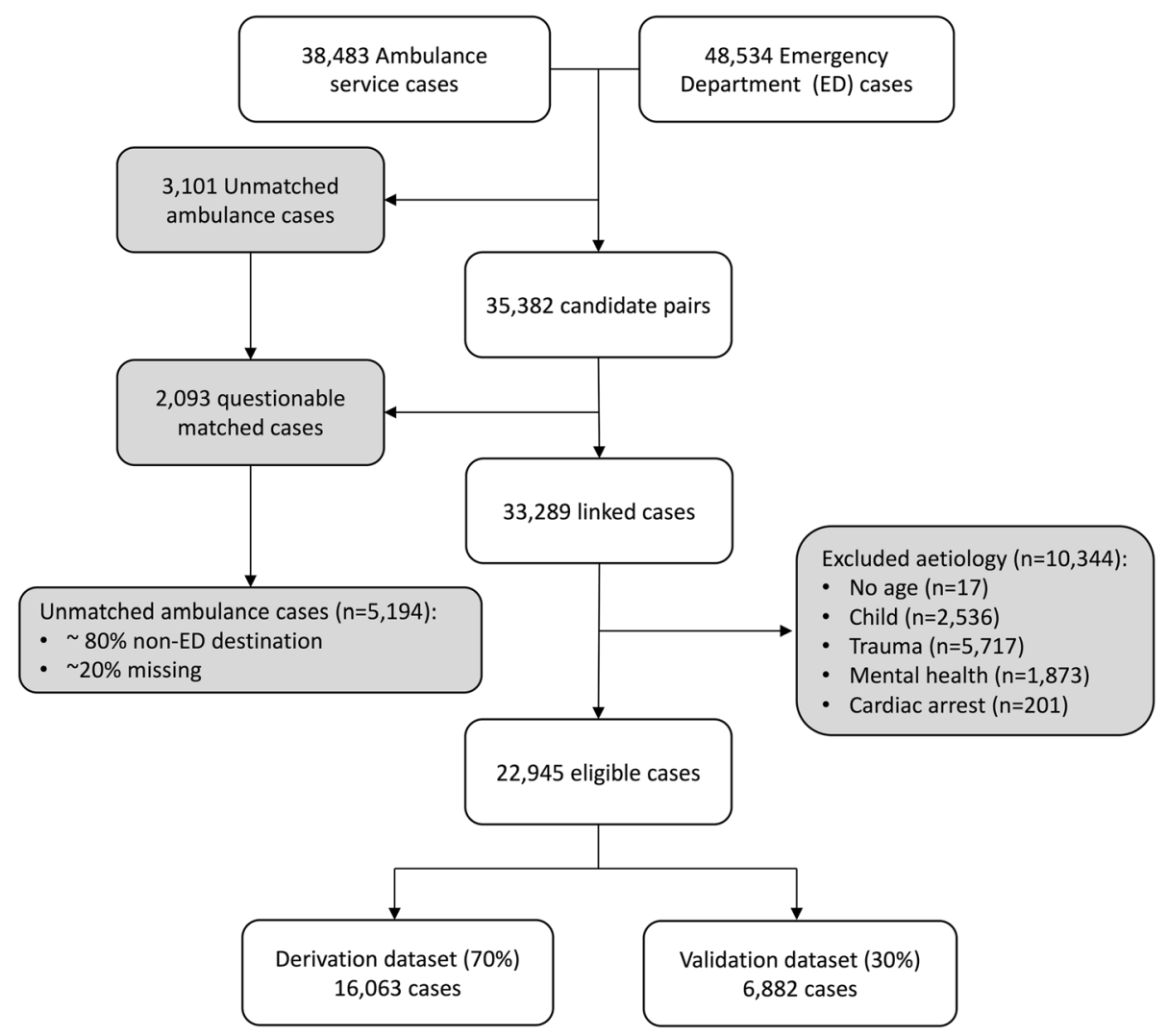

Fig. 1 Included cases

dataset was divided into a derivation dataset of 16063 cases (70\%) and a validation dataset of 6882 cases (30\%). The derivation dataset contained 593 instances of 'high risk' (3.7\%), sufficient cases to accommodate a model with 59 variables. The validation dataset contained 254 instances of 'high risk' (3.7\%), sufficient cases to accommodate 25 variables and to detect small differences in model performance [45]. Patient characteristics were consistent across derivation and validation cohorts (Table 2).

Univariable logistic regression analysis identified the following variables to be statistically significant predictors of 'high risk' in the derivation dataset: EMS impression, location, age, respirations, oxygen saturations ( $\mathrm{SpO} 2$ ), pulse, systolic blood pressure (SBP), diastolic blood pressure (DBP), temperature, blood sugar (BM), Skin, CBRT, left pupil reaction, right pupil reaction, left pupils size, right pupil size, GCS sum, GCS eye, GCS verbal, GCS motor, AVPU score (Additional file 1: Tables S3 \& S4).

A perfect correlation was identified between left and right pupil reactions, and a near perfect correlation was noted between left and right pupil size (Additional file 1: Figure S4). Differences in pupil size or pupil reactions are not known to be associated with sepsis. To avoid issues arising from inclusion of highly correlated variables, data concerning the left pupil were excluded from further analysis.

Strong correlations between GCS sum, GCS components (GCS eye, GCS verbal and GCS motor) and AVPU score (used to document level of consciousness) were identified. It is unclear which measure of level of consciousness would generate the most effective predictive model of sepsis. Three candidate models, using GCS sum, GCS components and AVPU score as their respective measure of consciousness, were generated.

Multivariable logistic regression analysis identified the following variables to be significant: location, age, respirations, oxygen saturations, pulse rate, systolic blood pressure, temperature, skin colour and level of consciousness. The number of instances each variable was selected, and the related Wald test statistic, for each model is reported in Table 3.

Categorisation of continuous variables is summarised in Table 4. Simple weighted scores to enable calculation of the SEPSIS score were obtained by rounding regression coefficients to the nearest integer (Additional file 1: Tables S5, S6 \& S7). Intervals for continuous variables with the same weighted score were merged to simplify calculation of the SEPSIS score (Additional file 1: Tables 
Table 2 Patient characteristics

\begin{tabular}{|c|c|c|}
\hline Variable & $\begin{array}{l}\text { Derivation } \\
n=16,063 \text { (70\%) }\end{array}$ & $\begin{array}{l}\text { Validation } \\
n=6,882(30 \%)\end{array}$ \\
\hline \multicolumn{3}{|l|}{ Location } \\
\hline Home, n (\%) & $11,408(71)$ & $4,964(72)$ \\
\hline Nursing home, n (\%) & $1,028(6)$ & $414(6)$ \\
\hline Other, n (\%) & $3,627(23)$ & $1,504(22)$ \\
\hline Age (years), mean (SD) & $63(21)$ & $62(21)$ \\
\hline \multicolumn{3}{|l|}{ Gender } \\
\hline Male, n (\%) & $7,884(49)$ & $3,346(49)$ \\
\hline Respirations (breaths/min), mean (SD) & $20(6)$ & $20(6)$ \\
\hline Oxygen saturation (\%), mean (SD) & $96(5)$ & $96(5)$ \\
\hline Heart rate (beats/min), mean (SD) & $92(24)$ & $92(24)$ \\
\hline Systolic blood pressure (mmHg), mean (SD) & $133(27)$ & $133(27)$ \\
\hline Diastolic blood pressure $(\mathrm{mmHg})$, mean (SD) & $78(17)$ & $78(17)$ \\
\hline Temperature $\left({ }^{\circ} \mathrm{C}\right)$, mean $(\mathrm{SD})$ & $36.8(0.9)$ & $36.8(0.9)$ \\
\hline Blood sugar (mmol/L), mean (SD) & $7.0(3.4)$ & $7.0(3.3)$ \\
\hline Glasgow Coma Score, median (IQR) & $15(15-15)$ & $15(15-15)$ \\
\hline \multicolumn{3}{|l|}{ Capillary bed refill time } \\
\hline Normal (<2s), n (\%) & $15,319(95)$ & $6,567(95)$ \\
\hline Delayed (> 2s), n (\%) & $744(5)$ & $315(5)$ \\
\hline \multicolumn{3}{|l|}{ Skin } \\
\hline Normal, n (\%) & $10,366(73)$ & $5,320(77)$ \\
\hline Pallor, n (\%) & $2,669(19)$ & $1,037(15)$ \\
\hline Flushed, $n(\%)$ & $856(6)$ & $359(5)$ \\
\hline Cyanosed, n (\%) & $181(1)$ & $83(1)$ \\
\hline Jaundice, n (\%) & $92(0.6)$ & $51(0.7)$ \\
\hline Mottled, n (\%) & $53(0.4)$ & $20(0.2)$ \\
\hline Rash, n (\%) & $21(0.1)$ & $12(0.1)$ \\
\hline Pupil size (mm), median (IQR) & $3(3-4)$ & $3(3-4)$ \\
\hline \multicolumn{3}{|l|}{ Pupil reaction } \\
\hline Brisk, n (\%) & $13,447(93)$ & $6,462(94)$ \\
\hline Sluggish, n (\%) & $923(6)$ & $381(6)$ \\
\hline Fixed, n (\%) & $128(0.8)$ & $39(0.5)$ \\
\hline \multicolumn{3}{|l|}{ NICE risk } \\
\hline No risk (no infection), n (\%) & 13,083 (81.4) & $5,607(81.5)$ \\
\hline Infection, n(\%) & $2980(18.6)$ & $1275(18.5)$ \\
\hline Low risk, n (\%) & $1,048(6.5)$ & $448(6.5)$ \\
\hline Moderate risk, n (\%) & $1,339(8.3)$ & $573(8.3)$ \\
\hline High risk, n (\%) & $593(3.7)$ & $254(3.7)$ \\
\hline
\end{tabular}

S8, S9 \& S10). The SEPSIS score is defined as the sum of the simplified weighted scores for each variable.

Relative performance of the three parallel models is reported in Table 5. The model utilising GCS sum as the measure of consciousness was calculated to have the best performance statistically. The final parsimonious model, with merged intervals and weighted scores, is reported in Table 6.

The calibration slope for the derivation and validation datasets was 1.0 and 0.97 respectively, suggesting the
SEPSIS score has adequate fit. The AUROC was 0.87 (95\% CI 0.85-0.88) for the derivation dataset and 0.86 (95\% CI 0.84-0.88) for the validation dataset. We report performance measures for each point score of the SEPSIS score in Additional file 1: Table S11, and categorise patients as low likelihood $(<10 \%)$, moderate likelihood (10-20\%) or high likelihood (>20\%) by applying different thresholds for the SEPSIS score (see Fig. 2).

Where the SEPSIS score indicates greater than $20 \%$ likelihood of 'high risk' at ED (SEPSIS score $\geq 5$ ), we 
Table 3 Selection of variables for inclusion in multivariable models

\begin{tabular}{|c|c|c|c|c|c|c|}
\hline \multirow{2}{*}{$\begin{array}{l}\text { Predictor } \\
\text { variable }\end{array}$} & \multicolumn{3}{|c|}{ Incidence of variable selection } & \multicolumn{3}{|l|}{ Wald test $p$-value } \\
\hline & GCS (sum) model & GCS (components) model & AVPU model & GCS (sum) model & GCS (components) model & AVPU model \\
\hline Location & 50 & 50 & 50 & 0.002 & 0.004 & 0.003 \\
\hline Age & 50 & 50 & 50 & $<0.001$ & $<0.001$ & $<0.001$ \\
\hline Gender & 0 & 0 & 0 & - & - & - \\
\hline Resps & 50 & 50 & 50 & $<0.001$ & $<0.001$ & $<0.001$ \\
\hline $\mathrm{SpO} 2$ & 50 & 50 & 50 & $<0.001$ & $<0.001$ & $<0.001$ \\
\hline Pulse & 50 & 50 & 50 & $<0.001$ & $<0.001$ & $<0.001$ \\
\hline SBP & 50 & 50 & 50 & $<0.001$ & $<0.001$ & $<0.001$ \\
\hline $\mathrm{DBP}$ & 0 & 0 & 0 & - & - & - \\
\hline Temp & 50 & 50 & 50 & $<0.001$ & $<0.001$ & $<0.01$ \\
\hline BM & 1 & 1 & 0 & $0.86^{*}$ & $0.85^{*}$ & $0.87^{*}$ \\
\hline Skin & 50 & 50 & 50 & 0.007 & 0.007 & 0.014 \\
\hline CBRT & 0 & 0 & 0 & - & - & - \\
\hline RPupilReact & 11 & 12 & 8 & $0.42^{*}$ & $0.41^{*}$ & $0.46^{*}$ \\
\hline RPupilSize & 0 & 0 & 0 & - & - & - \\
\hline GCS_sum & 50 & NA & NA & $<0.001$ & NA & NA \\
\hline GCS_eye & NA & 0 & NA & NA & - & NA \\
\hline GCS_verbal & NA & 50 & NA & NA & $<0.001$ & NA \\
\hline GCS_motor & NA & 0 & NA & NA & - & NA \\
\hline AVPU & NA & NA & 50 & NA & NA & $<0.001$ \\
\hline
\end{tabular}

SPO2 peripheral oxygen saturation, SBP systolic blood pressure, $D B P$ diastolic blood pressure, Temp temperature (C), $B M$ blood sugar mmol/L, $C B R T$ capillary bed refill time, GCS Glasgow coma score, AVPU alert, verbal, pain or unresponsive

${ }^{*}$ Did not reach statistical significance

observed satisfactory performance characteristics as reported in Table 7. If, as per the NICE sepsis guideline [NG51], the presence of infection is required before a diagnosis of sepsis can be made [12], then in the validation cohort of 6882 adult patients, 195 (2.8\%) patients were classified as being having 'high risk', and 6687 (97.2\%) were classified as not having 'high risk'. Among those patients classified as 'high risk', 95 (48.7\%) did have 'high risk' (true positive), while 100 (51.3\%) patients had their risk of sepsis overestimated i.e. were incorrectly identified as having 'high risk' (false positive). Within the 100 false positive cases, 79 (40.5\%) patients had 'moderate risk' and 21 (10.8\%) had 'low risk' on arrival at the ED. Among patients identified as not septic, 6528 (95.6\%) did not have sepsis (true negative), while 159 (62.6\%) did have 'high risk' on arrival at the ED but were incorrectly classified by the SEPSIS score as not having sepsis (false negatives).

\section{Discussion}

Screening tool performance is commonly described in terms of sensitivity, specificity, positive predictive value (PPV) and positive likelihood ratio (PLR). Sensitivity describes the ability of a test to correctly identify those with the disease (true positive rate), whereas specificity describes the ability of a test to correctly identify those without the disease (true negative rate). PPV represents the proportion of patients with positive test who actually have the disease, while the PLR shows how much more likely someone is to get a positive test if he/she has the disease, compared with a person without disease [55].

The performance characteristics of several existing screening tools used to support paramedic recognition of sepsis are reported in Table 8.

Existing data may suggest the PreSep score is the best performing sepsis screening tool. However, when applied to the same validation dataset used to test the SEPSIS score, the PreSep score remains more sensitive (0.61 (95\%CI $0.55-0.67))$, but has poorer specificity 0.95 (95\%CI 0.95-0.96), PPV 0.33 (95\%CI $0.29-0.37$ ) and PLR 12.76 (95\%CI 11.03-14.76). These data suggest the PreSep score may not in fact be the most useful for identifying those patients at risk of severe illness or death from sepsis by the bedside paramedic.

In this work, a threshold of SEPSIS score $\geq 3$ has a sensitivity of 0.80 (95CI $0.74-0.84$ ) specificity of 0.93 (95\%CI 0.93-0.94), PPV of 0.32 (95\%CI $0.28-0.36)$ and PLR of 12.17 (95\%CI 10.90-13.59). Adopting a threshold of SEPSIS score $\geq 5$ has a sensitivity of $0.37 \quad(95 \% \mathrm{CI}$ $0.31-0.44)$ specificity of 0.98 (95\%CI $0.98-0.99)$, PPV of 
Table 4 Continuous variable intervals

\begin{tabular}{|c|c|}
\hline Variable & Interval \\
\hline \multirow[t]{8}{*}{ Age } & below 40 (reference) \\
\hline & 40 to 49 \\
\hline & 50 to 59 \\
\hline & 60 to 69 \\
\hline & 70 to 79 \\
\hline & 80 to 89 \\
\hline & 90 to 99 \\
\hline & 100 plus \\
\hline \multirow[t]{11}{*}{ Respirations } & below 10 \\
\hline & 10 to 20 (reference) \\
\hline & 21 to 25 \\
\hline & 26 to 30 \\
\hline & 31 to 35 \\
\hline & 36 to 40 \\
\hline & 41 to 45 \\
\hline & 46 to 50 \\
\hline & 51 to 55 \\
\hline & 56 to 60 \\
\hline & 60 plus \\
\hline \multirow[t]{11}{*}{ Pulse } & below 60 \\
\hline & 60 to 100 (reference) \\
\hline & 101 to 110 \\
\hline & 111 to 120 \\
\hline & 21 to 130 \\
\hline & 131 to 140 \\
\hline & 141 to 150 \\
\hline & 151 to 160 \\
\hline & 161 to 170 \\
\hline & 171 to 180 \\
\hline & 180 plus \\
\hline \multirow[t]{11}{*}{ SBP } & below 60 \\
\hline & 60 to 69 \\
\hline & 70 to 79 \\
\hline & 80 to 89 \\
\hline & 90 to 99 \\
\hline & 100 to 120 (reference) \\
\hline & 121 to 129 \\
\hline & 130 to 139 \\
\hline & 140 to 149 \\
\hline & 150 to 159 \\
\hline & 160 plus \\
\hline \multirow[t]{3}{*}{$\mathrm{SpO} 2$} & above 93 (reference) \\
\hline & 89 to 93 \\
\hline & 85 to 88 \\
\hline
\end{tabular}

Table 4 Continuous variable intervals (Continued)

\begin{tabular}{ll}
\hline Variable & Interval \\
\hline Temperature & below 85 \\
& below 35 \\
& 35.0 to 35.5 \\
& 35.6 to 36.0 \\
& 36.1 to 36.5 \\
& 36.6 to 37.4 (reference) \\
& 37.5 to 38.0 \\
& 38.1 to 38.5 \\
& 38.6 to 39.0 \\
& 39.1 to 39.5 \\
& 39.6 to 40.0 \\
& above 40 \\
& $3-9$ \\
GCS & $10-12$ \\
& $13-14$ \\
& 15 (reference) \\
\hline
\end{tabular}

SBP systolic blood pressure, SpO2 peripheral oxygen saturations, GCS Glasgow coma score

0.49 (95\%CI $0.42-0.56)$ and PLR of 24.8 (95\%CI $19.3-$ 31.9 ). In terms of patients, a SEPSIS score $\geq 3$ correctly identified 202 patients with 'high risk', missed 52 patients and incorrectly identified that 433 had sepsis when in fact they did not. When adopting a threshold of SEPSIS score $\geq 595$ patients with 'high risk' were correctly identified and 159 patients missed and the number of patients incorrectly classified as 'high risk' was lower at 100.

Deciding what threshold to adopt for a 'positive' identification is a system level decision. Many systems will favour sensitivity to ensure cases are not missed but this needs to be balanced against significant over triage and the impact on resources this may have. Indeed, previous definitions for sepsis have been criticised for being overly sensitive with inadequate specificity [33, 34]. On this basis we suggest adopting a cut-off $\mathrm{SEPSIS} \geq 5$ to favour specificity and reduce false positive cases as reflected in the increased PLR. However, we recognise that many systems/clinicians may prefer to adopt a lower cut-off to increase sensitivity.

Table 5 Comparison of models

\begin{tabular}{lll}
\hline Model & AIC statistic & Brier score \\
\hline Model using GCS sum & $2,854.1$ & 0.0321 \\
Model using GCS components & $2,864.4$ & 0.0321 \\
Model using AVPU & $3,315.0$ & 0.0325 \\
\hline
\end{tabular}

GCS Glasgow coma score, AVPU alert, verbal, pain or unresponsive 
Table 6 SEPSIS score

\begin{tabular}{|c|c|c|c|c|c|}
\hline \multirow[b]{2}{*}{ Variable } & \multirow[b]{2}{*}{$\beta_{i}$} & \multicolumn{2}{|l|}{$\underline{95 \% ~ C l}$} & \multirow[b]{2}{*}{$p$ value } & \multirow{2}{*}{$\begin{array}{l}\text { Score } \\
\text { assigned }\end{array}$} \\
\hline & & lower & upper & & \\
\hline \multicolumn{6}{|l|}{ Age } \\
\hline Below 40 & reference & & & & 0 \\
\hline 40 to 60 & 0.35 & -0.15 & 0.86 & 0.17 & 0 \\
\hline Over 60 & 0.94 & 0.51 & 1.36 & $<0.001$ & 1 \\
\hline \multicolumn{6}{|l|}{ Respirations } \\
\hline Below 10 & -12.44 & -559.61 & 534.73 & 0.96 & 0 \\
\hline 10 to 20 & reference & & & & 0 \\
\hline 21 to 40 & 0.90 & 0.66 & 1.14 & $<0.001$ & 1 \\
\hline 40 to 60 & 1.72 & 1.26 & 2.18 & $<0.001$ & 2 \\
\hline 60 plus & -11.77 & -1970.04 & 1946.51 & 0.99 & 0 \\
\hline \multicolumn{6}{|l|}{ SpO2 } \\
\hline Above 93 & reference & & & & 0 \\
\hline Below 94 & 1.03 & 0.80 & 1.26 & $<0.001$ & 1 \\
\hline \multicolumn{6}{|l|}{ Pulse } \\
\hline Below 60 & -0.56 & -1.40 & 0.28 & 0.19 & 0 \\
\hline 60 to 100 & reference & & & & 0 \\
\hline 101 to 140 & 0.75 & 0.51 & 0.99 & $<0.001$ & 1 \\
\hline 141 to 160 & 1.67 & 1.27 & 2.08 & $<0.001$ & 2 \\
\hline Over 160 & 0.60 & -0.16 & 1.35 & 0.12 & 0 \\
\hline \multicolumn{6}{|l|}{ SBP } \\
\hline Below 60 & 0.50 & -1.53 & 2.52 & 0.63 & 0 \\
\hline 60 to 99 & 0.65 & 0.33 & 0.97 & $<0.001$ & 1 \\
\hline 100 to 120 & reference & & & & 0 \\
\hline 121 to 160 & -0.21 & -0.47 & 0.05 & 0.11 & 0 \\
\hline Over 160 & -0.72 & -1.10 & -0.34 & $<0.001$ & -1 \\
\hline \multicolumn{6}{|l|}{ GCS (sum) } \\
\hline 15 & reference & & & & 0 \\
\hline 13 to 15 & -0.13 & -0.48 & 0.21 & 0.45 & 0 \\
\hline 3 to 12 & 0.78 & 0.47 & 1.09 & $<0.001$ & 1 \\
\hline \multicolumn{6}{|l|}{ Temperature } \\
\hline Below 36.6 & -0.20 & -0.48 & 0.09 & 0.18 & 0 \\
\hline 36.6 to 37.4 & reference & & & & 0 \\
\hline 37.5 to 39.5 & 0.97 & 0.71 & 1.23 & $<0.001$ & 1 \\
\hline Above 39.5 & 1.71 & 1.23 & 2.18 & $<0.001$ & 2 \\
\hline \multicolumn{6}{|l|}{ Skin } \\
\hline Normal & reference & & & & 0 \\
\hline Jaundice, pallor, mottling & 0.51 & 0.27 & 0.75 & $<0.001$ & 1 \\
\hline \multirow[t]{2}{*}{ Any other } & 0.23 & -0.08 & 0.55 & 0.14 & 0 \\
\hline & & & \multicolumn{2}{|c|}{ Maximum score } & 11 \\
\hline
\end{tabular}




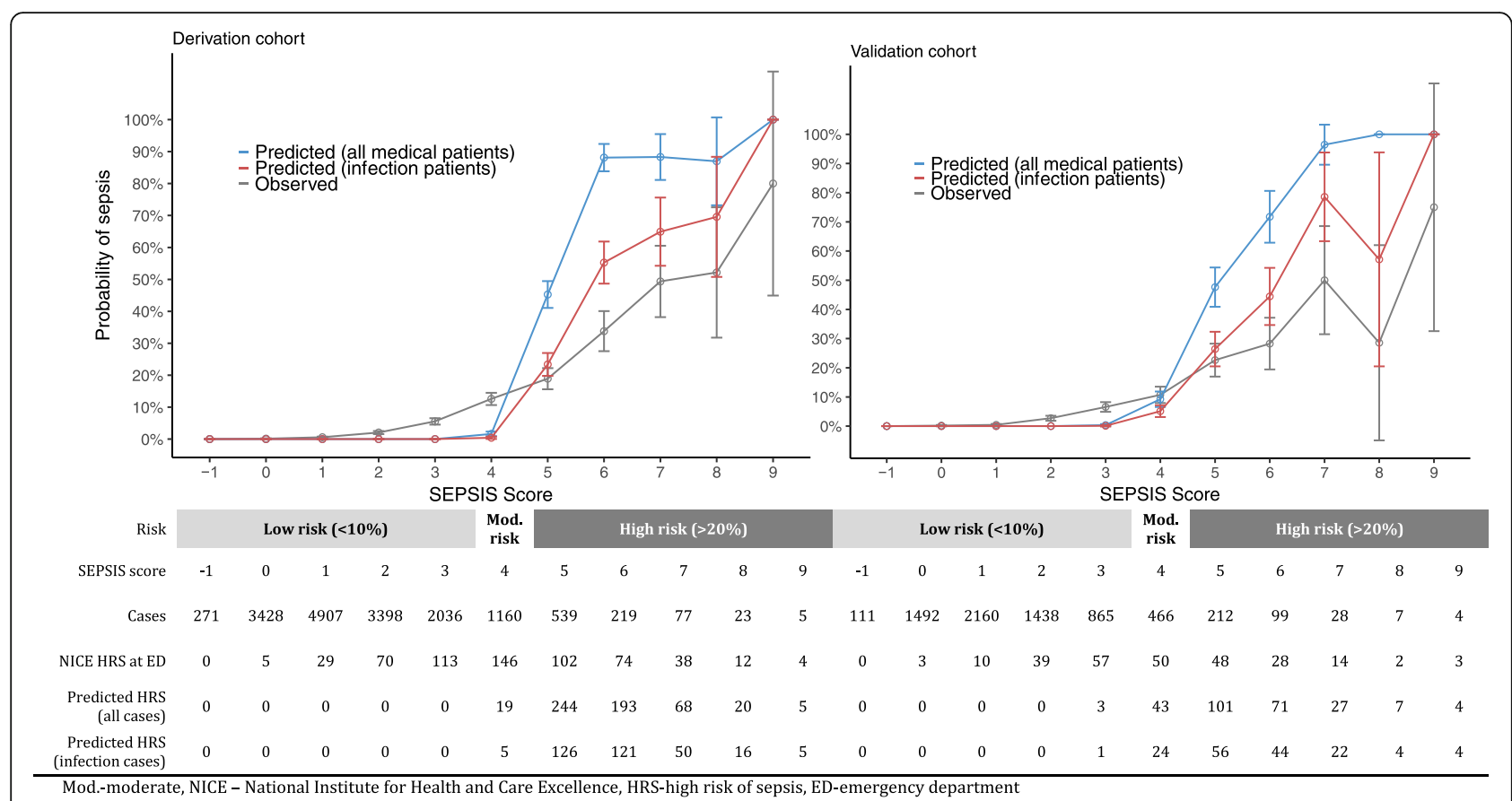

Fig. 2 Observed vs expected probability of sepsis. Mod.-moderate, HRS-high risk of severe illness or death from sepsis, ED-emergency department

Potentially important variables have been omitted from the SEPSIS score. Lactate is commonly used to help stratify severity among patients with sepsis [12, 61]. Lactate is not measured by ambulance crews in the participating ambulance service, therefore it was not available for consideration during SEPSIS score development. However, it has been reported that inclusion of prehospital lactate does not improve prehospital identification of sepsis [62]. Secondly, Hunter et al. argued that end-

Table 7 Comparison of performance between datasets (SEPSIS score $\geq 5$ )

\begin{tabular}{lcl}
\hline Estimate & $\begin{array}{c}\text { Derivation cohort } \\
n=16063\end{array}$ & $\begin{array}{l}\text { Validation cohort } \\
n=6882\end{array}$ \\
\hline Undifferentiated medical cases (estimate(95\% confidence interval)) \\
Sensitivity & $0.39(0.35-0.43)$ & $0.37(0.31-0.44)$ \\
Specificity & $0.96(0.96-0.96)$ & $0.96(0.96-0.97)$ \\
Positive predictive value & $0.27(0.24-0.30)$ & $0.27(0.23-0.32)$ \\
Negative predictive value & $0.98(0.97-0.98)$ & $0.98(0.97-0.98)$ \\
Positive likelihood ratio & $9.48(8.35-10.76)$ & $9.72(7.96-11.87)$ \\
Negative likelihood ratio & $0.64(0.60-0.68)$ & $0.65(0.59-0.72)$ \\
Infection present (estimate(95\% confidence interval)) & \\
Sensitivity & $0.39(0.35-0.43)$ & $0.37(0.31-0.44)$ \\
Specificity & $0.99(0.98-0.99)$ & $0.98(0.98-0.99)$ \\
Positive predictive value & $0.50(0.45-0.55)$ & $0.49(0.42-0.56)$ \\
Negative predictive value & $0.98(0.97-0.98)$ & $0.98(0.97-0.98)$ \\
Positive likelihood ratio & $26.1(22.2-30.1)$ & $24.8(19.3-31.9)$ \\
Negative likelihood ratio & $0.62(0.58-0.66)$ & $0.64(0.58-0.70)$ \\
\hline
\end{tabular}

tidal carbon dioxide $\left(\mathrm{EtCO}_{2}\right)$ measured by EMS was an important predictor of sepsis, severe sepsis and mortality, reporting an AUROC of 0.99 (95\%CI 0.99-1.0), 0.80 (95\%CI $0.73-0.86)$ and 0.70 (95\%CI $0.57-0.83)$ respectively [63]. Although $\mathrm{EtCO}_{2}$ can be measured by EMS personnel in the participating ambulance service, it is currently only measured when undertaking advanced airway interventions. It was thus seldom available for consideration in the SEPSIS score. It remains to be seen if inclusion of either of these variables would improve the performance of the SEPSIS score.

Stratification of the likelihood of 'high risk' on arrival at the ED, using the SEPSIS score, may help inform the provision of prehospital care, and/or the destination to which the patient is transferred. Although a SEPSIS score $\geq 5$ has high specificity, careful consideration is warranted before utilising the SEPSIS score to initiate treatment. Current evidence does not support routine prehospital administration of antibiotics [21]. In addition, appropriate antibiotic stewardship, and the need to obtain venous blood samples to culture pathogens prior to antibiotic administration, must be considered before implementing intervention strategies.

Ours is the first study to develop a prehospital sepsis screening tool using data from a UK ambulance service and the first to utilise the NICE high risk of severe illness or death from sepsis classification as the primary outcome measure. Ours is also the only such study to employ multiple imputation to manage missing data. A strength of this study is the primary outcome measure 
Table 8 Reported performance of alternate screening tools

\begin{tabular}{|c|c|c|c|c|}
\hline Screening tool & Sensitivity $(95 \% \mathrm{Cl})$ & Specificity $(95 \% \mathrm{CI})$ & PPV (95\% Cl) & NPV $(95 \% \mathrm{Cl})$ \\
\hline \multicolumn{5}{|l|}{ Press } \\
\hline Polito [56] & $0.85(N R)$ & 0.47 (NR) & $0.19(\mathrm{NR})$ & $0.96(N R)$ \\
\hline \multicolumn{5}{|l|}{ PreSep } \\
\hline Bayer [57] & $0.85(0.77-0.92)$ & $0.86(0.82-0.90)$ & $0.63(\mathrm{NR})$ & $0.95(\mathrm{NR})$ \\
\hline Jouffrey [58] & $0.92(N R)$ & 0.29 (NR) & $0.41(N R)$ & $0.88(N R)$ \\
\hline \multicolumn{5}{|l|}{ Robson tool (severe sepsis) } \\
\hline McClelland [24] & $0.30(0.12-0.47)$ & $0.77(0.60-0.95)$ & NR & $N R$ \\
\hline Wallgren [27] & $0.93(N R)$ & NR & NR & NR \\
\hline \multicolumn{5}{|l|}{ Robson tool (sepsis) } \\
\hline McClelland [24] & $0.43(0.28-0.58)$ & $0.14(0.0-0.40)$ & $N R$ & NR \\
\hline Bayer [57] & $0.95(N R)$ & 0.43 (NR) & 0.32 (NR) & $0.97(N R)$ \\
\hline Wallgren [27] & $0.75(\mathrm{NR})$ & NR & $N R$ & NR \\
\hline Dorsett [59] & $0.47(0.31-0.62)$ & $0.80(0.71-0.87)$ & NR & NR \\
\hline \multicolumn{5}{|l|}{ qSOFA } \\
\hline Dorsett [59] & $0.16(0.07-0.31)$ & $0.97(0.92-0.99)$ & NR & NR \\
\hline Jouffroy [58] & $0.62(N R)$ & 0.16 (NR) & $0.29(\mathrm{NR})$ & 0.44 (NR) \\
\hline Tusgul (ICU admission) [60] & $0.36(0.27-0.47)$ & NR & NR & NR \\
\hline
\end{tabular}

$\mathrm{Cl}$ confidence interval, $\mathrm{NR}$ not reported, $I C U$ intensive care unit

was determined using objective data from the ED record, rather than ED clinician diagnosis or International Classification of Disease (ICD) code, maximising specificity for the outcome measure. However, the SEPSIS score has been derived and internally validated with a retrospective data sample from a single centre which limits generalisability of the findings. In addition, it has not yet been clinically demonstrated that patients with high risk of serious illness or death from sepsis, as per the NICE guideline, benefit from early antibiotic therapy.

\section{Conclusion}

We derived and internally validated a prehospital model that predicts risk of severe illness or death from sepsis as per NICE guideline NG51 on arrival at the ED. We used routine EMS data, linked to ED records, in a heterogeneous medical population, to develop the SEPSIS score. The SEPSIS score could be a valuable tool for identifying sepsis patients in need of early antibiotic therapy. It requires external validation and assessment of performance when in use by ambulance clinicians.

\section{Additional file}

Additional file 1: Table S1. Excluded candidate predictor variables. Table S2 R-Hat statistics. Table S3. Logistic Regression of continuous candidate predictor variables. Table S4. Logistic regression of categorical candidate predictor variables. Table S5. Multivariable logistic regression model utilising GCS sum Table S6. Multivariable logistic regression model utilising GCS components. Table S7. Multivariable logistic regression model utilising AVPU. Table S8. Final weighted scores for candidate model using GCS sum. Table S9. Final weighted scores for candidate model using GCS components. Table S10. Final weighted scores for candidate model using AVPU. Table S11. Operating characteristics for the SEPSIS score. Figure S1. Convergence plots. Figure S2. Density plots. Figure S3. Box and whisker plots. Figure S4. Colinearity between candidate predictor variables. (DOCX $3170 \mathrm{~kb}$ )

\section{Acknowledgements}

The team is indebted to Krupa Suthar and Catherine White for their input concerning patient and public perspective while developing the project, Jenny Lumley-Holmes and Bhupinder Patel for their efforts in locating the relevant ambulance data fields and to Andrew Fraser and Sevilay NizamBasha for their help in locating the relevant hospital data.

\section{Authors' contributions}

MAS, GDP, PKK conceived the study idea. MR and MW facilitated data extraction at UHNS and WMAS respectively. MAS cleaned the data, performed all statistical analyses and drafted the manuscript. PKK supervised the study, advised on statistical methods and revised the manuscript for important intellectual content. GDP supervised the study and revised the manuscript for important intellectual content. DG advised on use of R packages, assisted with statistical analysis and revised the manuscript for important intellectual content. MR and MW revised the manuscript for important intellectual content. All authors approved the final manuscript.

\section{Funding}

This study was supported by a National Institute for Health Research Clinical Doctoral Research Fellowship awarded to MAS (CDRF-2012-05-058). The funders had no role in study design, data collection and analysis, decision to publish, or preparation of the manuscript.

\section{Competing interests}

GDP is a NIHR Senior Investigator. The remaining authors have no competing interests.

\section{Author details}

${ }^{1}$ Clinical Trials Unit, University of Warwick, Coventry, UK. ${ }^{2}$ West Midlands Ambulance Service NHS Foundation Trust, Dudley, UK. ${ }^{3}$ Midlands Air 
Ambulance, Dudley, UK. ${ }^{4}$ Royal Stoke University Hospital, Stoke on Trent, UK. ${ }^{5}$ Heart of England NHS Foundation Trust, Birmingham, UK.

\section{Received: 12 February 2019 Accepted: 3 July 2019 Published online: 16 July 2019}

\section{References}

1. Dellinger RP, et al. Surviving sepsis campaign: international guidelines for management of severe sepsis and septic shock: 2012. Crit Care Med. 2013; 41(2):580-637

2. Fleischmann C, et al. Assessment of global incidence and mortality of hospital-treated Sepsis. Current estimates and limitations. Am J Respir Crit Care Med. 2016:193(3):259-72.

3. Esteban A, et al. Sepsis incidence and outcome: contrasting the intensive care unit with the hospital ward. Crit Care Med. 2007:35(5):1284-9.

4. Wang HE, et al. National estimates of severe sepsis in United States emergency departments. Crit Care Med. 2007;35(8):1928-36.

5. Studnek JR, et al. The impact of emergency medical services on the ED care of severe sepsis. Am J Emerg Med. 2012;30(1):51-6.

6. Wang $\mathrm{HE}_{\text {, et }}$ al. Opportunities for emergency medical services care of sepsis. Resuscitation. 2010;81(2):193-7

7. Ibrahim I, Jacobs IG. Can the characteristics of emergency department attendances predict poor hospital outcomes in patients with sepsis? Singap Med J. 2013:54(11):634-8

8. Groenewoudt M, et al. Septic patients arriving with emergency medical services: a seriously ill population. Eur J Emerg Med. 2014:21(5):330-5.

9. Roest AA, Stoffers J, Pijpers E, Jansen J, Stassen PM. Ambulance patients with nondocumented sepsis have a high mortality risk. Eur J Emerg Med. 2017;24(1):36-43.

10. van der Wekken LCW, Alam N, Holleman F, van Exter P, Kramer MHH, Nanayakkara PWB. Epidemiology of Sepsis and its recognition by emergency medical services personnel in the Netherlands. Prehosp Emerg Care. 2015;20(1):90-96.

11. Femling J, et al. EMS patients and walk-in patients presenting with severe sepsis: differences in management and outcome. South Med J. 2014; 107(12):751-6.

12. National Institute for Health Care Excellence. Sepsis: recognition, diagnosis and early management. [ng51]. London: NICE; 2016.

13. Liu VX, Fielding-Singh V, Greene JD, Baker JM, Iwashyna TJ, Bhattacharya J, Escobar GJ. The timing of early antibiotics and hospital mortality in Sepsis. Am J Respir Crit Care Med. 2017;196(7):856-63.

14. Seymour CW, et al. Time to treatment and mortality during mandated emergency Care for Sepsis. N Engl J Med. 2017;376(23):2235-44.

15. Moyer $P$, et al. Development of systems of care for ST-elevation myocardial infarction patients: the emergency medical services and emergency department perspective. Circulation. 2007;116(2):e43-8

16. Abdullah AR, et al. Advance hospital notification by EMS in acute stroke is associated with shorter door-to-computed tomography time and increased likelihood of administration of tissue-plasminogen activator. Prehosp Emerg Care. 2008;12(4):426-31.

17. American College of Emergency Physicians. Trauma care systems development, evaluation, and funding. Policy statement. Ann Emerg Med. 2012;60(2):249-50.

18. Guerra WF, et al. Early detection and treatment of patients with severe sepsis by prehospital personnel. J Emerg Med. 2013;44(6):1116-25.

19. Band RA, et al. Arriving by emergency medical services improves time to treatment endpoints for patients with severe sepsis or septic shock. Acad Emerg Med. 2011:18(9):934-40.

20. Chamberlain D. Prehospital administered intravenous antimicrobial protocol for septic shock: a prospective randomized clinical trial. Crit Care. 2009:13:S130-1.

21. Alam N, et al. Prehospital antibiotics in the ambulance for sepsis: a multicentre, open label, randomised trial. Lancet Respir Med. 2018;6(1):40-50.

22. Seymour CW, et al. Understanding of sepsis among emergency medical services: a survey study. J Emerg Med. 2012;42(6):666-77.

23. Erwin A, et al. Can paramedics accurately diagnose sepsis and severe sepsis in the field? Acad Emerg Med. 2011;1:S23-4.

24. McClelland $\mathrm{G}$, Jones J. A pilot study exploring the accuracy of pre-hospital sepsis recognition in the north east ambulance service. J Paramed Pract. 2015:7(9):459-65.

25. Shiuh T, et al. An emergency medical services sepsis protocol with point-ofcare lactate accurately identifies out-of-hospital patients with severe infection and sepsis. Ann Emerg Med. 2012;1:S44.
26. Travers A, et al. Can paramedics diagnose sepsis in the prehospital setting? A feasibility study. Can J Emerg Med. 2013;15:S55.

27. Wallgren UM, et al. Identification of adult septic patients in the prehospital setting: a comparison of two screening tools and clinical judgment. Eur J Emerg Med. 2014;21(4):260-5.

28. Cudini D, Smith K, Bernard S, Stephenson M, Andrew E, Cameron P, Board J. Can pre-hospital administration reduce time to initial antibiotic therapy in septic patients? Emerg Med Aust. 2019. https://doi.org/10.1111/1742-6723.13282.

29. Báez AA, et al. Prehospital Sepsis project (PSP): knowledge and attitudes of United States advanced out-of-hospital care providers. Prehosp Disaster Med. 2013;28(02):104-6.

30. Kaukonen KM, et al. Systemic inflammatory response syndrome criteria in defining severe sepsis. N Engl J Med. 2015;372(17):1629-38.

31. Shime N. A survey of the competency of ambulance service personnel in the diagnosis and management of Sepsis. J Emerg Med. 2015:49(2):147-51.

32. Smyth MA, Brace-McDonnell SJ, Perkins GD. Identification of adults with sepsis in the prehospital environment: a systematic review. BMJ Open. 2016; 6(8):e011218.

33. Churpek MM, Zadravecz FJ, Winslow C, Howell MD, Edelson DP. Incidence and prognostic value of the systemic inflammatory response syndrome and organ dysfunctions in Ward patients. Am J Respir Crit Care Med. 2015;192(8):958-64.

34. Vincent $J$, Beumier M. Diagnostic and prognostic markers in sepsis. Expert Rev Antibiotics Infection Ther. 2013;11(3):265-75.

35. Robson W, Nutbeam T, Daniels R. Sepsis: a need for prehospital intervention? Emerg Med J. 2009;26(7):535-8.

36. Collins GS, et al. Transparent reporting of a multivariable prediction model for individual prognosis or diagnosis (TRIPOD). Ann Intern Med. 2015; 162(10):735-6.

37. van Buuren S, et al. Package 'mice'. [Computer software]. 2015. Retrieved from: https://CRAN.R-project.org/package=mice.

38. Robitzsch A, et al. Package 'Miceadds'. [Computer software]. 2014. Retrieved from: http://CRAN.R-project.org/package=miceadds.

39. Kuhn M. Caret package. J Stat Softw. 2008;28(5):1-26

40. Harrell F. Regression coefficients and scoring rules. J Clin Epidemiol. 1996; 49(7):819

41. Harrell F. Regression modeling strategies: with applications to linear models, logistic and ordinal regression, and survival analysis. New York: Springer; 2015.

42. Harrell FE, Lee KL, Mark DB. Tutorial in biostatistics multivariable prognostic models: issues in developing models, evaluating assumptions and adequacy, and measuring and reducing errors. Stat Med. 1996;15:361-87.

43. Harrell FE, et al. Development of a clinical prediction model for an ordinal outcome: the World Health Organization multicentre study of clinical signs and etiological agents of pneumonia, Sepsis and meningitis in young infants. Stat Med. 1998;17(8):909-44.

44. Royston $\mathrm{P}$, et al. Prognosis and prognostic research: developing a prognostic model. Br Med J. 2009;338:b604.

45. Steyerberg E. Clinical prediction models: a practical approach to development, validation, and updating. New York: Springer Science \& Business Media; 2008

46. Steyerberg EW, et al. Internal validation of predictive models: efficiency of some procedures for logistic regression analysis. J Clin Epidemiol. 2001; 54(8):774-81.

47. Vergouwe $Y$, et al. Substantial effective sample sizes were required for external validation studies of predictive logistic regression models. J Clin Epidemiol. 2005;58(5):475-83.

48. López-Ratón M, et al. OptimalCutpoints: an R package for selecting optimal cutpoints in diagnostic tests. J Stat Softw. 2014;61(8):1-36.

49. Lele SR, et al., Package 'ResourceSelection'. [Computer software]. 2016. Retrieved from: http://CRAN.R-project.org/package=ResourceSelection

50. Hilden J, Habbema JD, Bjerregaard B. The measurement of performance in probabilistic diagnosis. II Trustworthiness of the exact values of the diagnostic probabilities. Methods Archive. 1978;17:227-37.

51. Steyerberg EW, et al. Assessing the performance of prediction models: a framework for some traditional and novel measures. Epidemiology (Cambridge, Mass). 2010;21(1):128-38.

52. Kramer AA, Zimmerman JE. Assessing the calibration of mortality benchmarks in critical care: the Hosmer-Lemeshow test revisited. Crit Care Med. 2007;35(9):2052-6.

53. Sing T, et al. ROCR: visualizing classifier performance in R. Bioinformatics. 2005;21(20):3940-1.

54. Stevenson, M., M.M. Stevenson, I. BiasedUrn, Package 'epiR'. 2018 Recuperado el. 
55. Sedighi I. Interpretation of diagnostic tests: likelihood ratio vs. predictive value. Iran J Pediatr. 2013;23(6):717.

56. Polito CC, et al. Prehospital recognition of severe sepsis: development and validation of a novel EMS screening tool. Am J Emerg Med. 2015;33(9): $1119-25$.

57. Bayer O, Schwarzkopf D, Stumme C, Stacke A, Hartog CS, Hohenstein C, Winning J. An early warning scoring system to identify septic patients in the prehospital setting: the PRESEP score. Acad Emerg Med. 2015;22(7):868-71.

58. Jouffroy $R$, et al. Prehospital triage of septic patients at the SAMU regulation: comparison of qSOFA, MRST, MEWS and PRESEP scores. Am J Emerg Med. 2017.

59. Dorsett M, et al. GSOFA has poor sensitivity for prehospital identification of severe sepsis and septic shock. Prehosp Emerg Care. 2017;21(4):489-97.

60. Tusgul S, et al. Low sensitivity of qSOFA, SIRS criteria and sepsis definition to identify infected patients at risk of complication in the prehospital setting and at the emergency department triage. Scand I Trauma Resusc Emerg Med. 2017;25(1):108

61. Singer $\mathrm{M}$, et al. The third international consensus definitions for sepsis and septic shock (sepsis-3). J Am Med Assoc. 2016;315(8):801-10.

62. Boland $\mathrm{LL}$, et al. Prehospital lactate measurement by emergency medical Services in Patients Meeting Sepsis Criteria. West J Emerg Med. 2016;17(5): 648-55.

63. Hunter $\mathrm{CL}$, et al. A prehospital screening tool utilizing end-tidal carbon dioxide predicts sepsis and severe sepsis. Am J Emerg Med. 2016;34(5):813-9.

\section{Publisher's Note}

Springer Nature remains neutral with regard to jurisdictional claims in published maps and institutional affiliations.

Ready to submit your research? Choose BMC and benefit from:

- fast, convenient online submission

- thorough peer review by experienced researchers in your field

- rapid publication on acceptance

- support for research data, including large and complex data types

- gold Open Access which fosters wider collaboration and increased citations

- maximum visibility for your research: over $100 \mathrm{M}$ website views per year

At $\mathrm{BMC}$, research is always in progress.

Learn more biomedcentral.com/submissions 